\title{
Pleasantness of odors as a function of the immediate stimulus context'
}

ARTHUR SANDUSKY AND ALLEN PARDUCCI

UNIVERSITY OF CALIFORNIA, LOS ANGELES

\begin{abstract}
Absolute category judgments of the pleasantness of different odors were obtained from 138 Ss. Scale values were determined, separately for each $\mathrm{S}$ and by a Thurstone analysis of group data. These values provided the basis for manipulating the stimulus range. The variance of the judgments of a subset of the odors increased with restriction of the range. The data were interpreted as consistent with range-frequency theory but not with the theory of adaptation level.
\end{abstract}

\section{Problem}

Contextual theories of judgment (e.g., Helson, 1964; Parducci, 1965) have been developed and tested using simple perceptual dimensions such as lifted weight or visual size. The standards for judgment are provided by the immediate stimulus context, past experience having relatively little effect upon judgments of this type of stimulus. For example, Ss are reluctant to judge a square either "large" or "small" until they have seen the other squares in the experiment.

Affective judgments seem less dependent upon the immediate stimulus context. Most Ss judge a stench "unpleasant," even when it is the first odor presented. However, contextual effects have been demonstrated for the pleasantness of odors, the same odor being judged less "unpleasant" when presented in a series of unpleasant odors (e.g., Beebe-Center, 1929).

The present research used affective judgments of odor to test range-frequency theory (Parducci, 1965)。A simple model for the theory assumes that the judge tends to divide his subjective range of stimulation into equal intervals, each of the available categories of judgment corresponding to one of the intervals or subranges. Thus, if the subjective context could be restricted to a narrower range of affective values, the odors within the restricted range would be judged with more extreme categories. This test is of particular interest in that the theory of adaptation level (Helson, 1964) implies that a difference in range has no effect upon judgment, the judgment of each stimulus depending only on its relationship to the mean of the contextual stimuli. By shifting the two end-values symmetrically, i.e., without changing the mean of the stimulus values, the present experiments provide a basis for discriminating between the two theories.

\section{Method}

\section{Experiment I}

Each of 98 college students ranked the 12 odors listed in Table 1. One week later, he was re-presented eight of these odors. The instructions were to judge
TABLE I

Odor Values and Means from Experiment II

\begin{tabular}{clcr} 
Rank & \multicolumn{1}{c}{ Odor } & $\begin{array}{c}\text { Scale } \\
\text { Value }\end{array}$ & $\begin{array}{r}\text { Mean } \\
\text { Judgment }\end{array}$ \\
\hline 1 & Methol Salicilate & 5.2 & 2.4 \\
2 & Safrol & 5.1 & 2.1 \\
3 & Eugenol & 4.4 & 1.5 \\
4 & Citric Acid & 4.0 & 0.8 \\
5 & Coumarin & 3.9 & 0.5 \\
6 & Menthol & 3.7 & 0.2 \\
7 & di-Camphor & 3.3 & -0.6 \\
8 & Ethyl Cinnimate & 3.0 & -0.9 \\
9 & Phenol Ether & 2.4 & -1.8 \\
10 & o-Bromotolulene & 2.2 & -2.3 \\
11 & Heptaldehyde & 2.1 & -2.4 \\
12 & Quinoline & 1.7 & -2.9 \\
\hline
\end{tabular}

them on a scale from "very, very unpleasant, -4, " to "very, very pleasant, +4, " with freedom to omit categories or to add new ones as seemed appropriate. Each $\mathrm{S}$ was presented the particular six odors that he had ranked 4 through 9 . The ranks of the extreme odors differed for the two experimental groups: each of the 49 full-range Ss was also presented the two odors that he had ranked 1 and 12; for the 49 restricted-range Ss, the two additional odors had been ranked 3 and 9 . The odors were sniffed from $100 \mathrm{cc}$, wide-mouth bottles at 20-sec. intervals, each odor being presented once in each of four successive randomized blocks.

\section{Results}

Although the differences between the ranks assigned the same odor by different Ss were often large, the correlation between ranks and the initial judgments one week later was .81. This index of test-retest reliability suggests that there is some advantage in scaling odor separately for each S. However, the individual differences, both in the total range of judgments and in the rank of the stimulus at each $S$ 's neutral point, remain disturbingly large in comparison with those obtained for simpler perceptual dimensions.

The log variance of each S's six mean judgments of the odors he had ranked 4 through 9 was used as the dependent variable, i.e., as the measure of the extremity of judgment. As predicted from rangefrequency theory, the mean log variance for the restricted-range condition, .564, was greater than that for the full-range condition, .482; but the difference was of only borderline statistical significance $(t=1.89$, $\mathrm{df}=96, \mathrm{p}<.10)$ 。 
The smallness of this difference may be accounted for by a second assumption of the range-frequency model: the judge tends to use each category with equal frequency. If judgments simply divided the range into equal intervals (the range tendency), Ss judging the full range would omit the moderately extreme categories that would have been assigned to the missing stimuli (to ranks 2, 3, 10, and 11). The frequency tendency prevents omission of these categories. The rangefrequency theory asserts that Ss compromise between the two tendencies, assigning the moderately extreme categories to ranks 4 and 9 . Since this would increase the value of the dependent variable for the full-range condition, it would reduce the differences associated with range. A second experiment was designed to exclude the confounding effects of the unequal spacing of the stimuli in Experiment I.

\section{Method}

\section{Experiment II}

Forty new Ss were exposed to all 12 odors before receiving the instructions for judgment. Half of them then judged the full set over four consecutive blocks. The means of their judgments are presented in Table 1, along with the Thurstone values obtained from Condition D scaling of these judgments (Torgerson, 1958, pp. 234-240). The remaining Ss were presented only the middle six odors (Table 1). As in Experiment I, each group was balanced for sex. Although initial, unjudged presentation of all 12 odors should provide a strong frame of reference, the range-frequency model predicts that the variance of the judgments assigned to the middle six odors should increase as Ss adjust to the restricted range. Adaptation-level theory again predicts no experimental effects since the mean of the scaled values is not varied.

\section{Results}

The mean log variances of the judgments of the middle six odors by the full-range Ss decreased over the four blocks of trials. This affective habituation was reported by Beebe-Center (1929). Presumably, the restricted-range Ss had the same tendency to habituate, but this was counteracted by the effects of restricting their range so that the mean of their log variances increased over blocks of trials. Analysis of the linear component of the trend of the log variances over the four blocks indicated that the difference in trend associated with range was statistically significant $(t=2.88, \mathrm{df}=38, \mathrm{p}<.01)$ 。

\section{Diseussion}

The results of these two experiments are consistent with range-frequency theory. Contrary to adaptation-level theory, the judgments are not determined solely by the relationships between the judged stimuli and the stimulus mean. For with constant mean, the scale of judgment spreads to fit the range of stimuli, even when the scale is open-ended. Although a previous experiment had demonstrated this range effect with lifted weights, the effect appeared to depend upon the use of a closed set of categories (Harvey \& Campbell, 1963).

The demonstration of the range effect with an open-ended scale and particularly with such strongly affective materials argues for the generality of the range-frequency approach. Past experience with extremely pleasant or unpleasant odors might have been expected to reduce the effects of the immediate stimulus range more effectively than would past experience with extreme values on other dimensions. Simple psychophysical materials have been used to evaluate contextual theories just because psychophysical judgments are so dependnent upon the immediate stimulus context.

Although it seems important to test the generality of contextual theories with value judgments, odors present unusual experimental difficulties. The pleasantness of odors is not known to be associated with any single physical continuum, and the psychological differences between odors are multidimensional. This makes the separate odors distinctive and relatively easy to identify. Insofar as Ss try to judge consistently, identification reduces the possibility of contextual shifts. And since individual differences are extraordinarily large, both for stimulus ranks and for spread of categories, the use of odors limits the power of this type of experiment. In view of the demonstration by Young (1923) that individual differences in the affective ranking of odors are consistent over a period of years, it is striking that the present Ss adjusted so rapidly to a restriction of range.

\section{References}

Beebe-Center, J. G. The law of affective equilibrium. Amer. J Psychol., 1929, 41, 64-72.

Harvey, O. J., \& Campbell, D. T. Judgments of weight as affected by adaptation range, adaptation duration, magnitude of unlabeled anchor, and judgmental language. J.. exp. Psychol., 1963, 65, 12-21.

Helson, H. Adaptation-level theory. New York: Harper \& Row, 1964 Parducci, A. Category judgment: A range-frequency model. Psychol. Rev., 1965, 72, in press.

Torgerson, W. S. Theory and methods of scaling. New York: Wiley \& Sons, 1958.

Young, P. T. Constancy of affective judgments to odors. $J$. exp. Psychol., 1923, 6, 182-191.

Note

1. This research was supported by Public Health Service Grant HD-00923 and National Science Foundation Grant GB-1768. 